\title{
Dodecyl gallate induces apoptosis by upregulating the caspase-dependent apoptotic pathway and inhibiting the expression of anti-apoptotic Bcl-2 family proteins in human osteosarcoma cells
}

\author{
CHUN-HSIANG CHENG ${ }^{1 *}$, YEN-PO CHENG ${ }^{2,3^{*}}$, ING-LIN CHANG ${ }^{4}$, \\ HSIN-YAO CHEN ${ }^{4}$, CHIA-CHIEH WU ${ }^{4}$ and CHEN-PU HSIEH ${ }^{4 *}$ \\ ${ }^{1}$ Orthopedics \& Sports Medicine Laboratory; ${ }^{2}$ Division of Neurosurgery, Department of Surgery, Changhua Christian Hospital, \\ Changhua 500-06; ${ }^{3}$ Institute of Biomedical Sciences, College of Life Science, National Chung Hsing University, \\ Taichung 402; ${ }^{4}$ Department of Orthopedic Surgery, Changhua Christian Hospital, Changhua 500-06, Taiwan, R.O.C.
}

Received January 13, 2015; Accepted October 28, 2015

DOI: $10.3892 / \mathrm{mmr} .2015 .4717$

\begin{abstract}
Dodecyl gallate (DG) is a gallic acid ester that has been shown to inhibit tumor growth. The aim of this study was to investigate the mechanism by which DG induces antiproliferative and apoptotic effects in MG-63 human osteosarcoma cells. Dose- and time-dependent cytotoxic effects of DG were determined using an MTT assay. The results showed that the half-maximal inhibitory concentration $\left(\mathrm{IC}_{50}\right)$ of $\mathrm{DG}$ in MG-63 cells was $31.15 \mu \mathrm{M}$ at $24 \mathrm{~h}, 10.66 \mu \mathrm{M}$ at $48 \mathrm{~h}$, and $9.06 \mu \mathrm{M}$ at $72 \mathrm{~h}$. Flow cytometric analysis demonstrated that exposure to 20 and $40 \mu \mathrm{M}$ DG resulted in an increase in the sub-G1 phase population and in S-phase cell cycle arrest. Furthermore, western blot analysis of apoptosis-related protein expression revealed an increase in the activation of caspases 8 and 3, cleavage of poly (ADPribose) polymerase (PARP), and disruption of mitochondrial membrane permeability was measured by flow cytometry. An increase in the Bax/Bcl-2 ratio and a decrease in the expression of inhibitor of apoptosis protein (IAP) family members, namely X-linked inhibitor of apoptosis protein and survivin, were also observed following DG treatment. These data provide insight into the molecular mechanisms governing the ability of DG to induce apoptosis in human osteosarcoma cells in vitro.
\end{abstract}

Correspondence to: Mr. Chia-Chieh Wu and Mr. Chen-Pu Hsieh, Department of Orthopedic Surgery, Changhua Christian Hospital, 135 Nansiao Street, Changhua 500-06, Taiwan R.O.C.

E-mail: 50560@cch.org.tw

E-mail: 51114@cch.org.tw

*Contributed equally

Key words: dodecyl gallate, MG-63 cells, apoptosis, Bcl-2, caspase

\section{Introduction}

Osteosarcoma is the most common type of primary bone cancer in children and is associated with a high rate of metastasis, relapse and mortality. Approximately $80 \%$ of cases occur in the appendicular skeleton and the most common site of metastasis is the lung. The overall five-year survival rate of patients with the disease is $20-70 \%$ (1-3). Treatment strategies including chemotherapy, radical resection and irradiation followed by extensive rehabilitation can be effective in certain patients, particularly those with low-grade neoplasms; however, up to a third of patients who initially respond to treatment relapse $(4,5)$. Novel treatments are therefore urgently required (6).

A number of chemotherapeutic agents are derived from plants, such as paclitaxel (from Taxus brevifolia L.), vincristine (from Catharanthus roseus G. Don), podophyllotoxin (from Podophyllum peltatum L.) and camptothecin (from Camptotheca acuminata) (7). While they are effective treatments for different types of cancer, a number of these drugs are associated with serious side effects. Foods high in polyphenolic compounds may represent an alternative or adjunctive therapy for the prevention or treatment of cancer. Polyphenols, namely phenolic acids and flavonoids, are naturally occurring compounds found predominantly in fruits, vegetables and beverages (8), and a number of these have been shown to offer protection against various diseases, including cancer (9).

Gallic acid, an intermediate component of plant metabolism, and its ester derivative gallate have been shown to be associated with a wide variety of biological actions, including antioxidant, antifungal, antibacterial, antimalarial and antiherpetic activities (10-13). Dodecyl gallate (DG) has been shown to protect human cells from oxidative damage and to inhibit tumor growth while exhibiting low toxicity to normal cells $(14,15)$. In addition, DG has also been reported to induce apoptosis and inhibit the proliferation of leukemic cells, lymphocytes and melanoma cells derived from rats (16-18). It 
has also been demonstrated that DG is able to disrupt mitochondrial membrane permeability, promote cytochrome $c$ release into the cytosol resulting in caspase activation, and induce the degradation of DNA into oligonucleosomal fragments in the murine Wehi 231 B-cell lymphoma line (19). However, the mechanism of apoptosis induction by DG in tumor cells is not clearly understood. Thus, the aim of this study was to investigate the mechanism by which DG induces antiproliferative and apoptotic effects in MG-63 human osteosarcoma cells.

\section{Materials and methods}

Cell culture and reagents. The MG-63 human osteosarcoma cell line was obtained from the Bioresource Collection and Research Center (Hsinchu, Taiwan). Cells were cultured in Minimum Essential Medium (MEM; Gibco-BRL, Thermo Fisher Scientific, Waltham, MA, USA) supplemented with $10 \%$ fetal bovine serum (Gibco), 1\% penicillin/streptomycin (Gibco), $0.1 \mathrm{mM}$ non-essential amino acids (Gibco), and $1.0 \mathrm{mM}$ sodium pyruvate (Gibco) in $75-\mathrm{cm}^{2}$ tissue culture flasks. Cells were incubated at $37^{\circ} \mathrm{C}$ in a humidified atmosphere of $5 \% \mathrm{CO}_{2}$ in air. Medium was changed twice weekly and cells were subcultured once they reached $80-90 \%$ confluence. A stock solution (20 mM) of DG (Sigma-Aldrich, St. Louis, MO, USA) was prepared by dissolving $3.384 \mathrm{mg}$ of the compound in $0.5 \mathrm{ml}$ dimethyl sulfoxide (Sigma-Aldrich).

Cell viability assay. Cell viability was evaluated by the 3-(4,5-dimethylthiazol-2-y1)-2,5-diphenyltetrazolium bromide (MTT) assay as previously described (20). MTT was obtained from Amresco (St. Louis, MO, USA). Briefly, MG-63 cells were seeded in 96-well plates overnight and then treated with various concentrations of DG for 24, 48 or $72 \mathrm{~h}$. The optical density of the MTT formazan product was measured at a wavelength of $590 \mathrm{~nm}$ with a microplate reader (Thermo Multiskan SPECTRUM Thermo Fisher Scientific). Results are expressed as a percentage of the untreated controls. Data were calculated as the percentage of proliferation using the following formula: Proliferation $(\%)=($ ODtest-ODblank $) \times 100$, where ODtest and ODblank are the optical density (OD) of the test substances and the blank controls, respectively.

Cell cycle analysis. MG-63 cells were plated on 12-well plates at a density of $1 \times 10^{4}$ cells/well, treated with different concentrations of DG, and then incubated for $24 \mathrm{~h}$. Adherent cells were harvested with trypsin (Gibco), washed in phosphate-buffered saline (PBS), collected by centrifugation at $400 \mathrm{xg}$ for $10 \mathrm{~min}$, and then fixed with $75 \%$ ethanol at $4^{\circ} \mathrm{C}$ for $24 \mathrm{~h}$. Cell pellets were then collected by centrifugation at $400 \mathrm{x} \mathrm{g}$ for $10 \mathrm{~min}$ and incubated with propidium iodine (PI; Sigma-Aldrich) solution (0.1\% Triton X-100, $0.2 \mu \mathrm{g} / \mathrm{ml}$ Ribonuclease A and $40 \mu \mathrm{g} / \mathrm{ml} \mathrm{PI}$ ) for $30 \mathrm{~min}$. Cell cycle phase was determined by flow cytometry using a Cytomics FC500 cytometer (Beckman Coulter, Brea, CA, USA) and CXP Analysis Software version 2.1 (Beckman Coulter). Other materials and reagents not specified were obtained from Sigma-Aldrich or Merck Millipore (Billerica, MA, USA).
Annexin VIPI staining to detect apoptosis. MG-63 cells were plated on 12-well plates at a density of $1 \times 10^{4}$ cells/well for $24 \mathrm{~h}$. Cells were then treated with different concentrations of DG and incubated for $24 \mathrm{~h}$. Following incubation, cells were harvested with trypsin, washed with PBS and collected by centrifugation at $400 \mathrm{x} \mathrm{g}$ for $5 \mathrm{~min}$. After removal of the supernatant, cells were resuspended in $500 \mu \mathrm{l}$ of $1 \mathrm{X}$ Binding Buffer [10X Binding Buffer-100 mM HEPES (pH 7.4); $18 \mathrm{mM} \mathrm{CaCl}_{2}$; $50 \mathrm{mM} \mathrm{KCl} ; 1.5 \mathrm{M} \mathrm{NaCl}$; and $10 \mathrm{mM} \mathrm{MgCl}_{2}$ which had been diluted to $1 \mathrm{X}$ prior to use], to which $1 \mu \mathrm{l}$ Annexin $\mathrm{V}$-fluorescein isothiocyanate (FITC; BioVision, Milpitas, CA, USA) and $10 \mu 1$ PI (Sigma-Aldrich) were added. Cells were then incubated at room temperature for $15 \mathrm{~min}$ in the dark. Qualitative and quantitative assessments of apoptosis were conducted with a Muse Cell analyzer (Merck Millipore). Other materials and reagents not specified were obtained from Sigma-Aldrich or Merck.

Mitochondrial membrane potential assay. MG-63 cells were seeded on 12 -well plates for $24 \mathrm{~h}$ and then treated with different concentrations of DG for $1 \mathrm{~h}$. Cells were then harvested with trypsin, washed with PBS and collected by centrifugation at $400 \mathrm{x} g$ for $5 \mathrm{~min}$. After centrifugation, the supernatant was removed and the cell pellets were stained with the Muse MitoPotential kit (Merck Millipore) for $25 \mathrm{~min}$ at $37^{\circ} \mathrm{C}$ and data was analyzed by the Muse Cell Analyzer assays (Merck Millipore).

Western blot assay. MG-63 cells were lysed on ice for $30 \mathrm{~min}$ with radioimmunoprecipitation assay buffer (Merck Millipore) containing protease inhibitors (BioVision). Cells were then scraped off the dishes and centrifuged at $15,900 \times \mathrm{g}$ at $4^{\circ} \mathrm{C}$ for $10 \mathrm{~min}$, and the supernatant was collected. Equal amounts of protein $(30 \mu \mathrm{g})$ were loaded onto $8-12 \%$ polyacrylamide gels (Bio-Rad Laboratories, Hercules, CA, USA). Proteins were then transferred to polyvinylidene difluoride membranes (Millipore, Bedford, MA), which were blocked for $1 \mathrm{~h}$ with 5\% non-fat dried milk in $0.1 \%$ PBST (500 ml 1X PBS with $0.5 \mathrm{ml}$ Tween-20) at room temperature. Membranes were then incubated with primary antibodies against cleaved caspase-3 (cat. no. 9661; 1:1,000 dilution; Cell Signaling Technology Inc., Beverly, MA, USA), caspase-9 (cat. no. 9508; 1:1,000 dilution; Cell Signaling Technology Inc.), bcl-2 (cat. no. 2872; 1:1,000 dilution; Cell Signaling Technology Inc.), X-linked inhibitor of apoptosis protein (XIAP; cat. no. 2042; 1:1,000 dilution; Cell Signaling Technology Inc.), survivin (cat. no. 2808; 1:1,000 dilution; Cell Signaling Technology Inc.), glyceraldehyde 3-phosphate dehydrogenase (GAPDH) (cat. no. 2118; 1:1,000 dilution; Cell Signaling Technology Inc.), poly (ADPribose) polymerase (PARP; cat. no. 9542; 1:1,000 dilution; Cell Signaling Technology Inc.), bax (sc-493; 1:1,000 dilution; Santa Cruz Biotechnology Inc., Santa Cruz, CA, USA) and caspase-8 (NB100-56116; 1:1,000 dilution; Novus Biologicals, Littleton, CO, USA) overnight at $4^{\circ} \mathrm{C}$. Later, membranes were washed three times with PBST and incubated with horseradish peroxidase-conjugated goat anti-rabbit (cat. no. 7074; 1:10,000 dilution; Cell Signaling Technology Inc.) and horse anti-mouse (cat. no. 7076; 1:10,000 dilution; Cell Signaling Technology Inc.) secondary antibodies for $1 \mathrm{~h}$ at room temperature. After washing with PBS three times, the protein signals 
were detected by an enhanced chemiluminescence detection system (Merck-Millipore). The band densities were quantified using Image J software 1.42q (National Institutes of Health, Bethesda, MD, USA).

Statistical analysis. All data were obtained from at least three separate experiments and are expressed as the mean \pm standard deviation. Statistical comparisons of differences between groups were conducted using Student's t-test. $\mathrm{P}<0.05$ was considered to indicate a statistically significant difference. All statistical analyses were performed using the software package GraphPad Prism (Version 4.0, GraphPad Software; San Diego, CA, USA).

\section{Results}

Cytotoxic effect of DG on the MG-63 human osteosarcoma cell line. MG-63 cells were exposed to various concentrations $(6.25-100 \mu \mathrm{M})$ of DG for 24,48 or $72 \mathrm{~h}$, and cell viability was determined by the MTT assay. As shown in Fig. 1, the estimated $\mathrm{IC}_{50}$ value of DG in MG-63 cells was $31.15 \mu \mathrm{M}$ at $24 \mathrm{~h}$, $10.66 \mu \mathrm{M}$ at $48 \mathrm{~h}$, and $9.06 \mu \mathrm{M}$ at $72 \mathrm{~h}$. The viability of MG-63 cells decreased markedly in a dose- and time-dependent manner.

Effects of DG on cell cycle distribution in MG-63 cells. Flow cytometry was used to determine whether DG causes cell growth inhibition by inducing cell cycle arrest. MG-63 cells were exposed to a series of concentrations of DG for $24 \mathrm{~h}$. As shown in Fig. 2, exposure to DG at concentrations of 20 and $40 \mu \mathrm{M}$ for $24 \mathrm{~h}$ resulted in a significantly increased number of cells arrested in the $S$ phase. Additionally, the sub- $G_{1}$ population, which is an indication of cell death, increased significantly in the presence of 20 and $40 \mu \mathrm{M}$ DG.

Flow cytometric analysis of DG-induced apoptosis in MG-63 cells. To further investigate whether the growth inhibition induced by DG in human osteosarcoma cells was caused by apoptosis, MG-63 cells were treated with various concentrations of DG for $24 \mathrm{~h}$ and the percentage of apoptotic cells was measured by flow cytometry. As shown in Fig. 3, the percentages of cells demonstrating early stages of apoptosis (Annexin $\mathrm{V}^{+} / \mathrm{PI}^{-}$and lower right quadrant) and late stages of apoptosis and necrotic death (Annexin $\mathrm{V}^{+} / \mathrm{PI}^{+}$and upper right quadrant) increased in a dose-dependent manner.

$D G$ induces the loss of mitochondrial membrane potential. To determine whether DG-induced apoptosis involves the mitochondria-mediated apoptotic pathway, DG-treated cells were stained with the Muse MitoPotential kit and Muse Cell Analyzer assays were conducted. As shown in Fig. 4, treatment with 10-40 $\mu \mathrm{M}$ DG resulted in an increase depolarized/live percentage, indicating loss of mitochondria membrane potential. DG induced dose-dependent collapse of mitochondrial membrane potential. The results indicate that DG-induced apoptosis is mediated by the mitochondrial pathway.

Effects of DG on caspase activation in MG-63 cells. To further clarify the type of apoptotic pathway induced by DG, western blot analysis was used to detect the expression levels of cleaved

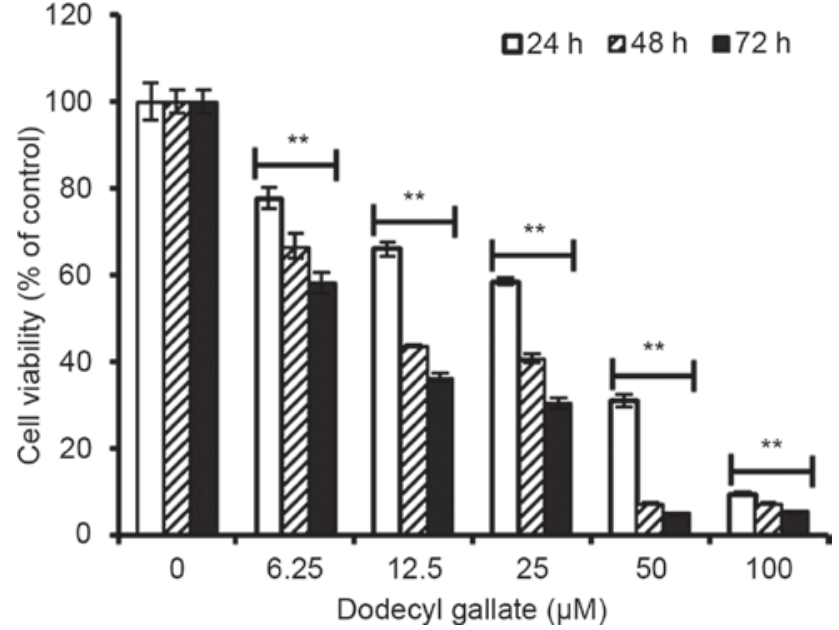

Figure 1. Cytotoxicity of dodecyl gallate in MG-63 cells. The cytotoxicity of dodecyl gallate in MG-63 cells was determined using the MTT assay and was shown to occur in a dose- and time-dependent manner. Each point is presented as the mean \pm standard deviation of three experiments. ${ }^{* *} \mathrm{P}<0.001$ as compared with the control group.

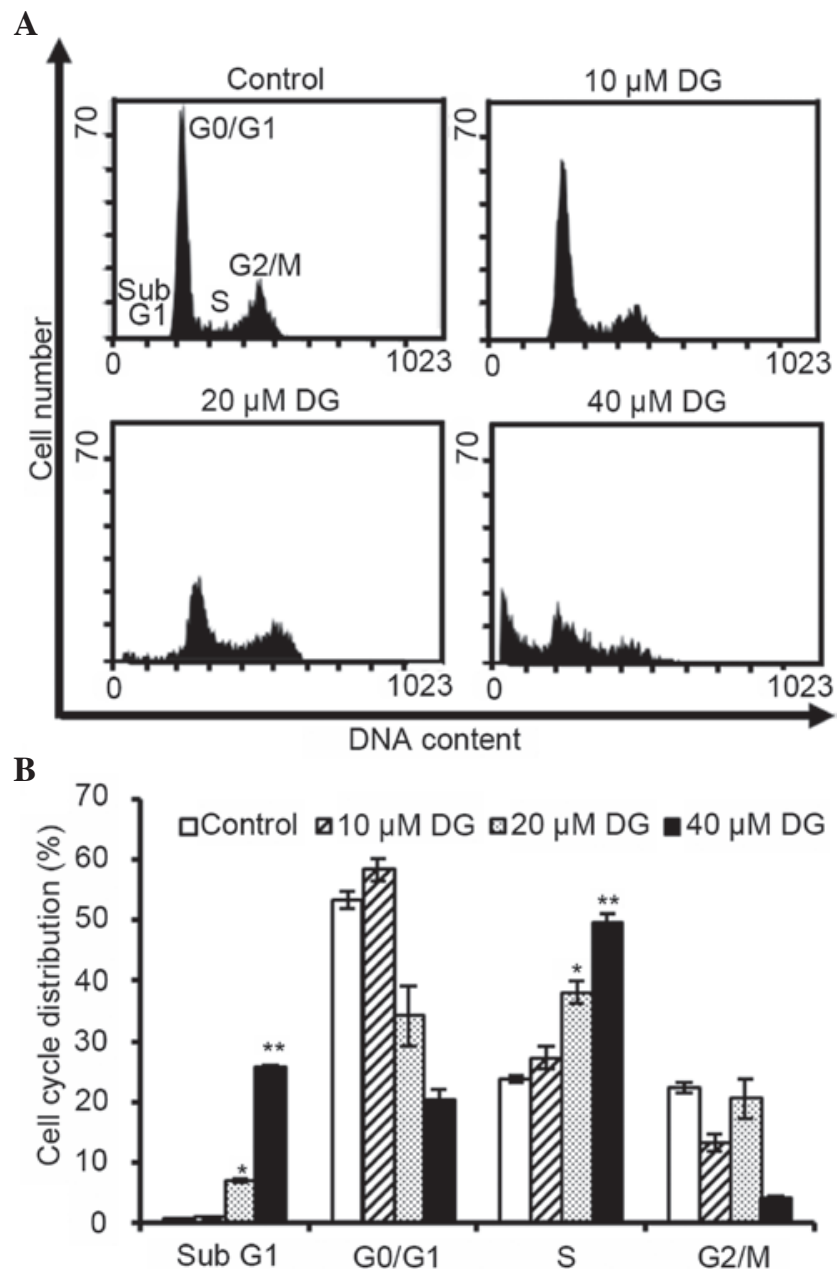

Figure 2. Effects of DG on cell cycle distribution in MG-63 cells. (A) Cell cycle analysis of DG-treated cells. Cells were treated with various concentrations of DG $(0,10,20$ and $40 \mu \mathrm{M})$ for $24 \mathrm{~h}$. Cell cycle distribution was determined by propidium iodide staining and subsequent flow cytometric analysis. The peaks on the graph correspond to the sub-G1, G0/G1, S and G2/M phases of the cell cycle. (B) Histogram showing the percentages of cells in each phase of the cell cycle. Data are representative of three independent experiments with similar results. ${ }^{*} \mathrm{P}<0.05$ and ${ }^{* *} \mathrm{P}<0.001$ as compared with the control group. DG, dodecyl gallate. 

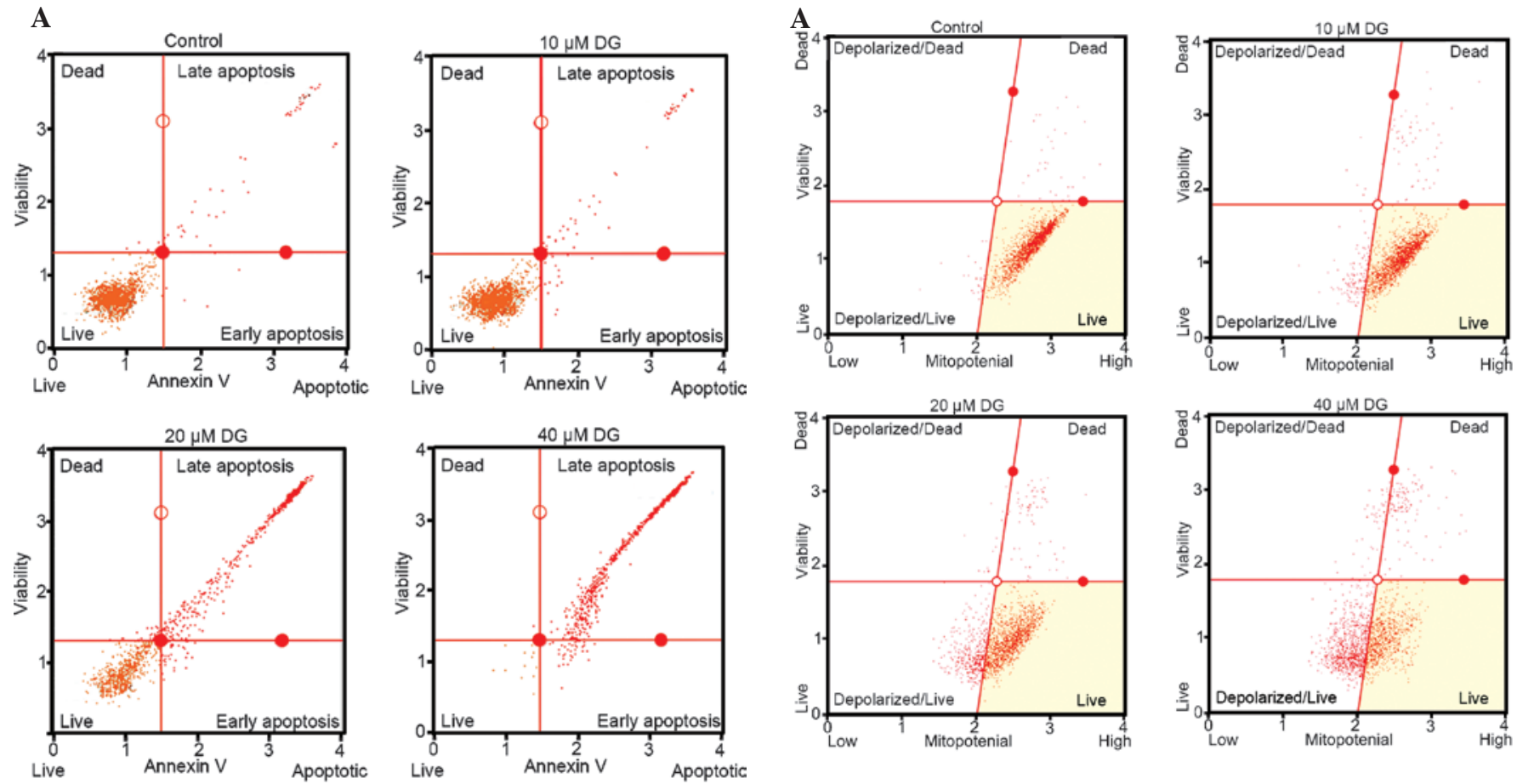

B

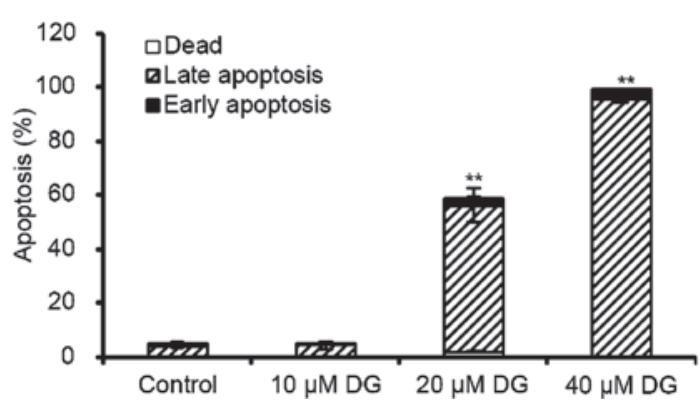

Figure 3. Flow cytometric analysis of DG-induced apoptosis in MG-63 cells. (A) Cells were treated with various concentrations of DG $(0,10,20$ and $40 \mu \mathrm{M}$ ) for $24 \mathrm{~h}$, followed by labeling for phosphatidylserine externalization with Annexin V and PI double-staining and subsequent Muse Cell analysis. (B) Histogram shows the percentages of apoptotic cells for each concentration of DG. Data are representative of three independent experiments with similar results. ${ }^{* *} \mathrm{P}<0.001$ as compared with the control group. DG, dodecyl gallate.

forms of caspase-8, caspase 9, caspase-3 and PARP. As shown in Fig. 5, levels of cleaved forms of caspase-3, caspase- 8 and PARP were higher in cells exposed to $20 \mu \mathrm{M}$ DG compared with those in the control group.

$D G$ decreases Bcl-2 and XIAP protein expression in MG-63 cells. To confirm that the mitochondrial pathway is involved in DG-induced apoptosis, the protein expression of Bax, a pro-apoptotic member of the Bcl-2 family of apoptotic apoptotic regulators, and $\mathrm{Bcl}-2$ protein, an anti-apoptotic member of the Bcl-2 family was examined. As shown in Fig. 5, treatment of MG-63 cells with DG for $24 \mathrm{~h}$ resulted in increased levels of $\mathrm{Bax} / \mathrm{Bcl}-2$ protein. In addition to measuring expression levels of members of the Bcl-2 family, the changes in expression of IAP family proteins were also investigated. The results showed that expression of two IAP family proteins, namely survivin and XIAP, were reduced following treatment with higher doses of DG, as shown in Fig. 6.

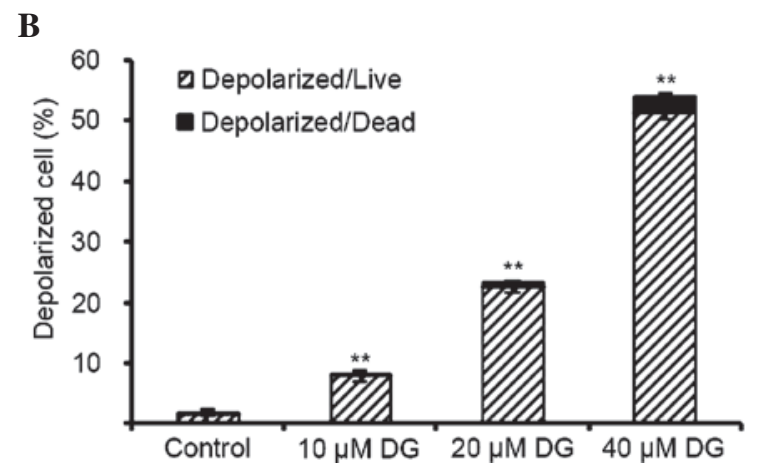

Figure 4. Effect of DG on mitochondrial membrane potential in MG-63 cells. (A) Cells were treated with various concentrations of DG $(0,10,20$ or $40 \mu \mathrm{M}$ ) for $1 \mathrm{~h}$. The cells were stained with the Muse MitoPotential kit determined using Muse Cell analysis. (B) Histogram shows the percentage of depolarization following treatment with each concentration of DG. Data are representative of three independent experiments with similar results. ${ }^{* *} \mathrm{P}<0.001$ as compared with the control group. DG, dodecyl gallate.

\section{Discussion}

Gallic acid is a naturally abundant plant phenolic compound in the human diet (21). Gallic acid derivatives, such as hydrogenated farnesyl gallate, DG, gallic acid laurylamide and cholesteryl gallate, have been shown to induce apoptosis in U937 and L1210 human monoblastic leukemia cells $(22,23)$. The molecular mechanism governing the movement of gallate into cells and its interaction with lipid membranes remains unclear. It has been reported that the lipophilic group on the dodecyl ester allows for its uptake into cells and organelles via lipophilic membranes. In addition, binding of the hydrophilic pyrogallol group of gallate to the hydrophilic portion of membrane surfaces results in disruption of membrane fluidity at the membrane lipid bilayer (17).

DG has been shown to exhibit antiproliferative effects in the B16F10 mouse melanoma cell line (24). The present results demonstrate that DG inhibits tumor growth (Fig. 1) with $\mathrm{IC}_{50}$ 
A
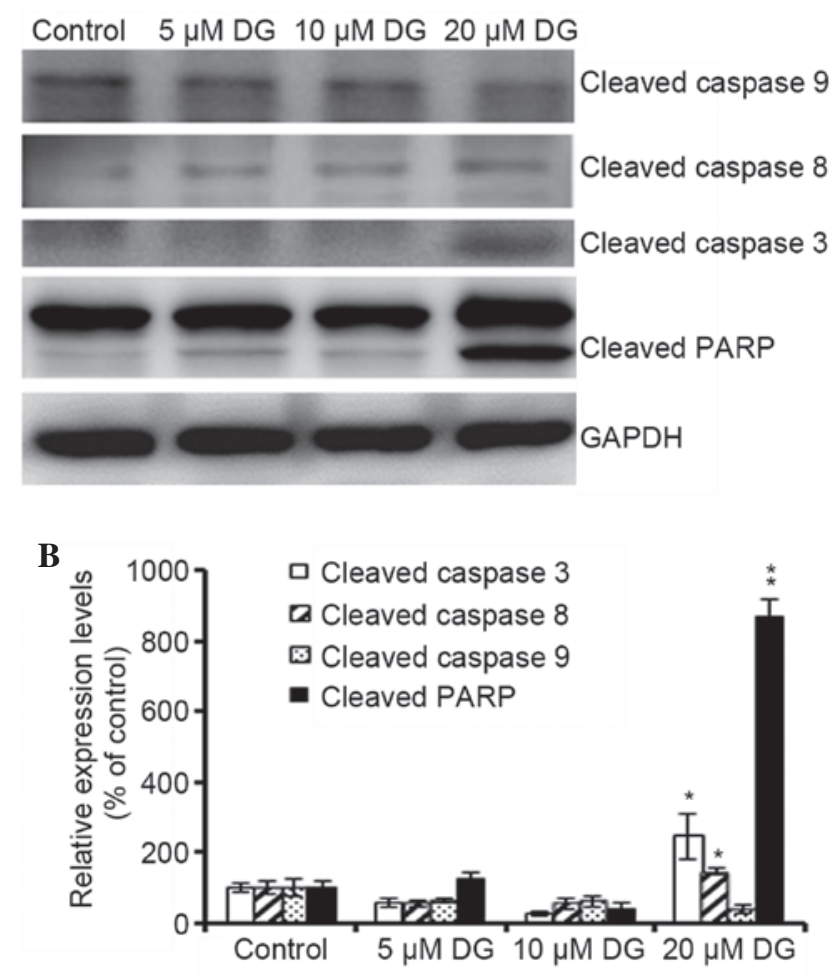

Figure 5. Effects of DG on caspase activation in MG-63 cells. (A) The cells were treated with various concentrations of DG $(0,5,10$ or $20 \mu \mathrm{M})$ for $24 \mathrm{~h}$. Total cell lysates were prepared, resolved by SDS-PAGE, and immunoblotted with the indicated antibodies to detect the cleaved forms of caspase- 8 , caspase-9, caspase-3 and PARP. GAPDH served as a loading control. (B) Results of cleaved caspase-8, caspase-9, caspase-3 and PARP protein levels after being normalized to the levels of GAPDH. Data are representative of three independent experiments with similar results. ${ }^{*} \mathrm{P}<0.05$ and $^{* *} \mathrm{P}<0.001$ as compared with the control group. DG, dodecyl gallate; PARP, poly (ADPribose) polymerase; GAPDH, glyceraldehyde 3-phosphate dehydrogenase.

values of $31.15 \mu \mathrm{M}$ at $24 \mathrm{~h}, 10.66 \mu \mathrm{M}$ at $48 \mathrm{~h}$ and $9.06 \mu \mathrm{M}$ at $72 \mathrm{~h}$. These values are similar to those reported by de Cordova et al (17), who showed that DG induced apoptosis in the B16F10 melanoma cell line.

Cell cycle arrest is a common phenomenon of cell growth inhibition (25). Calcabrini et al (15) showed that treatment with DG inhibited cell growth by arresting MCF-7 breast cancer cells in the G1 phase. By contrast, it was demonstrated that DG induced S-phase arrest in MG-63 cells. The difference in the type of cell cycle arrest caused by DG may be due to differences in cell type or species.

Apoptosis is governed by two predominant pathways, namely the extrinsic pathway, which is caused by the stimulation of pro-apoptotic cell surface receptor signal pathways, and the intrinsic pathway, which includes a cascade of reactions resulting in the activation of caspases. Apoptosis is defined by several biochemical criteria such as disruption of mitochondrial membrane potential, activation of caspase signaling, induction of DNA fragmentation of oligonucleosomal DNA, and the release of inter membrane mitochondrial proteins into the cytosol (25). DG has been shown to induce caspase-dependent apoptosis in human melanoma cells (17). In the present study, Annexin V-FITC/PI double staining was used to understand the mechanisms governing the anticancer actions of DG. It was demonstrated that DG $(10-40 \mu \mathrm{M})$ induced apoptosis in
A

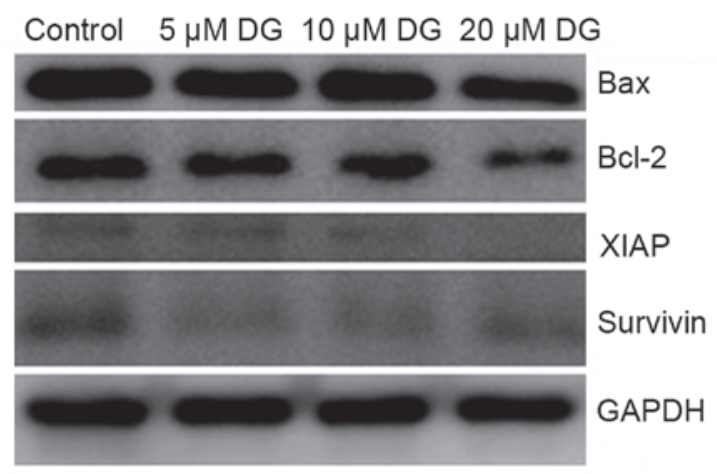

B

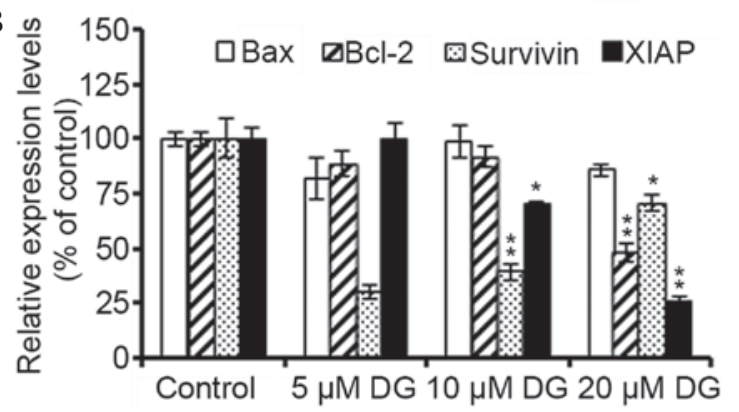

Figure 6. Decreased Bcl-2 and XIAP protein expression in MG-63 cells. (A) The cells were treated with various concentrations of DG $(0,5,10$ or $20 \mu \mathrm{M}$ ) for $24 \mathrm{~h}$. Total cell lysates were prepared, resolved by SDS-PAGE, and immunoblotted with the indicated antibodies to detect the cleaved forms of Bax, Bc1-2, XIAP and survivin. GAPDH served as a loading control. (B) Results of Bax, Bcl-2, XIAP and survivin protein levels after being normalized to the levels of GAPDH. Data are representative of three independent experiments with similar results. ${ }^{*} \mathrm{P}<0.05$ and ${ }^{* *} \mathrm{P}<0.001$ as compared with the control group. DG, dodecyl gallate; XIAP, X-linked inhibitor of apoptosis protein; GAPDH, glyceraldehyde 3-phosphate dehydrogenase.

a dose-dependent manner and activated caspase-8, caspase-3 and PARP cleavage. The intrinsic apoptotic pathway is regulated by members of the Bcl-2 family. Bcl-2 family proteins include anti-apoptotic proteins, such as Bcl-2, Bcl-XL, and Mcl-1, which inhibit apoptosis by preventing cytochrome $c$ release from the mitochondria, and pro-apoptotic proteins, such as Bad, Bax, and Bid, which facilitate apoptosis by promoting cytochrome $c$ release from mitochondria. Bax and $\mathrm{Bcl}-2$ combine to form of a Bax/Bcl-2 heterodimer or Bax/Bax and $\mathrm{Bcl}-2 / \mathrm{Bcl}-2$ homodimers thus maintaining the balance between expression levels of anti- and pro-apoptotic Bcl-2 family proteins in the cell $(17,25)$. Bcl-2 protein is located in the outer mitochondrial membrane, and its control of cell death effect major related with mitochondrial membrane structure and function. The $\mathrm{Bcl}-2$ protein inhibits the permeability of mitochondrial transition pores and prevents the collapse of mitochondrial membrane potential and release of pro-apoptotic factors into the cytosol $(15,26)$. Moreover, inhibitors of apoptosis can act directly by binding to activated caspases, such as caspase-3 and caspase-7 (27). It was demonstrated that $24 \mathrm{~h}$ treatment with DG resulted in an increase in the $\mathrm{Bax} / \mathrm{Bcl}-2$ ratio and a decrease in protein expression of anti-apoptotic members of the Bcl-2 family, namely Bcl-2, XIAP and survivin (Fig. 6).

In conclusion, this study demonstrated that DG induces apoptosis by upregulating the caspase-dependent apoptotic pathway and inhibiting the expression of anti-apoptotic Bcl-2 
proteins in human osteosarcoma cells. These findings provide useful information for the development of anticancer agents.

\section{Acknowledgements}

This study was supported by a grantfrom the Changhua Christian Hospital, Changhua, Taiwan (grant no. 1Y_103_0263).

\section{References}

1. Liang W, Li X, Li C, Liao L, Gao B, Gan H, Yang Z, Liao L and Chen X: Quercetin-mediated apoptosis via activation of the mitochondrial-dependent pathway in MG-63 osteosarcoma cells. Mol Med Rep 4: 1017-1023, 2011.

2. Ma JF, Liu L, Yang WJ, Zang LN and Xi YM: RNAi-mediated knockdown of relaxin decreases in vitro proliferation and invasiveness of osteosarcoma MG-63 cells by inhibition of MMP-9. Eur Rev Med Pharmacol Sci 17: 1102-1109, 2013.

3. Wang XF and Wang J: Icaritin suppresses the proliferation of human osteosarcoma cells in vitro by increasing apoptosis and decreasing MMP expression. Acta Pharmacol Sin 35: 531-539, 2014

4. Honicke AS, Ender SA and Radons J: Combined administration of EGCG and IL-1 receptor antagonist efficiently downregulates IL-1-induced tumorigenic factors in U-2 OS human osteosarcoma cells. Int J Oncol 41: 753-758, 2012.

5. Crompton BD, Goldsby RE, Weinberg VK, Feren R, O'Donnell RJ and Ablin AR: Survival after recurrence of osteosarcoma: A 20-year experience at a single institution. Pediatr Blood Cancer 47: 255-259, 2006.

6. Siclari VA and Qin L: Targeting the osteosarcoma cancer stem cell. J Orthop Surg Res 5: 78, 2010.

7. Ji SJ, Han DH and Kim JH: Inhibition of proliferation and induction of apoptosis by EGCG in human osteogenic sarcoma (HOS) cells. Arch Pharm Res 29: 363-368, 2006.

8. Naasani I, Oh-Hashi F, Oh-Hara T, Feng WY, Johnston J, Chan K and Tsuruo T: Blocking telomerase by dietary polyphenols is a major mechanism for limiting the growth of human cancer cells in vitro and in vivo. Cancer Res 63: 824-830, 2003.

9. Saint-Cricq De Gaulejac N, Provost C and Vivas N: Comparative study of polyphenol scavenging activities assessed by different methods. J Agric Food Chem 47: 425-431, 1999.

10. Manna SK, Kuo MT and Aggarwal BB: Overexpression of gamma-glutamylcysteine synthetase suppresses tumor necrosis factor-induced apoptosis and activation of nuclear transcription factor-kappaB and activator protein-1. Oncogene 18: 4371-4382, 1999.

11. Fiuza SM, Gomes C, Teixeira LJ, Girão da Cruz MT, Cordeiro MN, Milhazes N, Borges F and Marques MP: Phenolic acid derivatives with potential anticancer properties-a structure-activity relationship study. Part 1: methyl, propyl and octyl esters of caffeic and gallic acids. Bioorg Med Chem 12: 3581-3589, 2004.

12. Grundhöfer P, Niemetz R, Schilling G and Gross GG: Biosynthesis and subcellular distribution of hydrolyzable tannins. Phytochemistry 57: 915-927, 2001.
13. Klein $\mathrm{E}$ and Weber $\mathrm{N}$ : In vitro test for the effectiveness of antioxidants as inhibitors of thiyl radical-induced reactions with unsaturated fatty acids. J Agric Food Chem 49: 1224-1227, 2001.

14. Jagan S, Ramakrishnan G, Anandakumar P, Kamaraj S and Devaki T: Antiproliferative potential of gallic acid against diethylnitrosamine-induced rat hepatocellular carcinoma. Mol Cell Biochem 319: 51-59, 2008.

15. Calcabrini A, García-Martínez JM, González L, Tendero MJ, Ortuño MT, Crateri P, Lopez-Rivas A, Arancia G, González-Porqué P and Martín-Pérez J: Inhibition of proliferation and induction of apoptosis in human breast cancer cells by lauryl gallate. Carcinogenesis 27: 1699-1712, 2006.

16. Inoue M, Suzuki R, Koide T, Sakaguchi N, Ogihara Y and Yabu Y: Antioxidant, gallic acid, induces apoptosis in HL-60RG cells. Biochem Biophys Res Commun 204: 898-904, 1994.

17. de Cordova CA,Locatelli C,Assuncão LS, MatteiB,Mascarello A, Winter E, Nunes RJ, Yunes RA and Creczynski-Pasa TB: Octyl and dodecyl gallates induce oxidative stress and apoptosis in a melanoma cell line. Toxicol In Vitro 25: 2025-2034, 2011.

18. Nakagawa Y, Moldéus P and Moore G: Propyl gallate-induced DNA fragmentation in isolated rat hepatocytes. Arch Toxicol 72: 33-37, 1997.

19. Roy G, Lombardía M, Palacios C, Serrano A, Cespón C, Ortega E, Eiras P, Lujan S, Revilla Y and Gonzalez-Porqué P: Mechanistic aspects of the induction of apoptosis by lauryl gallate in the murine B-cell lymphoma line Wehi 231. Arch Biochem Biophys 383: 206-214, 2000.

20. Yan MY, Chien SY, Kuo SJ, Chen DR and Su CC: Tanshinone IIA inhibits BT-20 human breast cancer cell proliferation through increasing caspase 12, GADD153 and phospho-p38 protein expression. Int J Mol Med 29: 855-863, 2012.

21. Hsu CL, Lo WH and Yen GC: Gallic acid induces apoptosis in 3T3-L1 pre-adipocytes via a Fas- and mitochondrial-mediated pathway. J Agric Food Chem 55: 7359-7365, 2007.

22. Saeki K, Yuo A, Isemura M, Abe I, Seki T and Noguchi $H$ : Apoptosis-inducing activity of lipid derivatives of gallic acid. Biol Pharm Bull 23: 1391-1394, 2000.

23. Locatelli C, Rosso R, Santos-Silva MC, de Souza CA, Licínio MA, Leal P, Bazzo ML, Yunes RA and Creczynski-Pasa TB: Ester derivatives of gallic acid with potential toxicity toward L1210 leukemia cells. Bioorg Med Chem 16: 3791-3799, 2008.

24. Locatelli C, Leal PC, Yunes RA, Nunes RJ and Creczynski-Pasa TB: Gallic acid ester derivatives induce apoptosis and cell adhesion inhibition in melanoma cells: The relationship between free radical generation, glutathione depletion and cell death. Chem Biol Interact 181: 175-184, 2009.

25. Wu CS, Chen YJ, Chen JJ, Shieh JJ, Huang CH, Lin PS, Chang GC, Chang JT and Lin CC: Terpinen-4-ol induces apoptosis in human nonsmall cell lung cancer in vitro and in vivo. Evid Based Complement Alternat Med 2012: 818261, 2012.

26. Kowaltowski AJ, Cosso RG, Campos CB and Fiskum G: Effect of Bcl-2 overexpression on mitochondrial structure and function. J Biol Chem 277: 42802-42807, 2002.

27. Yang YL and Li XM: The IAP family: Endogenous caspase inhibitors with multiple biological activities. Cell Res 10: 169-177, 2000. 